\title{
ANALISIS PENDAPATAN DAN FAKTOR-FAKTOR YANG MEMPENGARUHI MINAT PETANI TERHADAP USAHATANI PADI SAWAH KECAMATAN MEUREUBO KABUPATEN ACEH BARAT
}

(Income Analysis And The Factors That Influence Farmer's Interest Toward Rice Farming Field In Meureubo Aceh Barat)

\author{
Lisa Oktaviani ${ }^{1}$, Azhar ${ }^{1}$, Mustafa Usman ${ }^{1 *}$ \\ ${ }^{1}$ Program Studi Agribisnis, Fakultas Pertanian, Universitas Syiah Kuala
}

\begin{abstract}
Abstrak - Usahatani padi merupakan suatu usaha yang penting di Indonesia. Penelitian ini bertujuan untuk mengetahui kelayakan usahatani padi sawah berdasarkan pendapatan yang diterima oleh petani dan pengaruh faktor pendapatan, pendidikan, lingkungan keluarga dan lingkungan masyarakat terhadap minat petani padi sawah di Kecamatan Meureubo Kabupeten Aceh Barat. Metode analisis yang digunakan pada penelitian ini adalah analisis pendapatan dan analisis statistik uji Chi-square. Hasil penelitian ini menunjukkan bahwa petani padi sawah telah mendapatkan pendapatan yang layak, nilai R/C adalah 2,11 (R/C> 1) dan hasil analisis uji Chi-square menunjukkan bahwa faktor pendapatan, lingkungan keluarga dan lingkungan masyarakat merupakan faktor yang berpengaruh signifikan terhadap minat petani sedangkan faktor pendidikan tidak memiliki pengaruh yang signifikan terhadap minat petani.

Kata Kunci: Usahatani Padi Sawah, Minat, Pendapatan, Pendidikan, Lingkungan Keluarga dan Lingkungan Masyarakat.
\end{abstract}

Abstract - Rice farming is an important effort in Indonesia. This study aims to determine the feasibility of rice farming based on income that received by the farmer and the influence of income, education,family environment and society toward the interest of farmer in Meureubo Aceh Barat. Method of analysis used in this reserach is the analysis of the revenue and statistical analysis Chi-square test. The results of this study indicate that the farmers have earned a proper income, the value of $\mathrm{R} / \mathrm{C}$ was $2.11(\mathrm{R} / \mathrm{C}>1)$ and the results of Chi-square test analysis showed that the factors of income, family and community environment arethe significant factor that affect the framer's interest while education factor has no significant effect on farmer's interest.

Keywords: Rice farming field, Interest, Income, Education, family environment and society environment.

\section{PENDAHULUAN}

Usahatani padi merupakan suatu usaha yang penting di Indonesia, selain sebagai penyedia kebutuhan pangan yaitu beras, usahatani padi juga menjadi penyedia lapangan kerja terbesar di Indonesia. Namun, dengan kemajuan tekhnologi pada era globalisasi sekarang, jumlah penduduk yang bekerja di sektor pertanian sebagai lapangan kerja utama, terus mengalami penurunan. Hal ini tidak sebanding dengan jumlah penduduk yang terus meningkat. Data BPS (2015), mencatat jumlah penduduk di Aceh pada tahun 2013 adalah sebesar 4.811.100 jiwa sedangkan pada tahun 2014 jumlah penduduk di Aceh adalah sebesar 
4.906.800 jiwa, dalam kurun waktu setahun terjadi peningkatan jumlah penduduk sebesar 95.700 jiwa.

Peningkatan jumlah penduduk selalu diikuti dengan peningkatan permintaan akan kebutuhan pangan yaitu beras. Namun, jumlah petani di Indonesia pada umumnya terus menurun. Survei pertanian yang dilakukan oleh Badan Pusat Statistik (BPS), menginformasikan bahwa Selama sepuluh tahun terjadi penurunan jumlah rumah tangga usaha tani sekitar 5 juta atau rata-rata turun sebesar 1,75\% per tahun. Lebih lanjut, data BPS provinsi Aceh, mencatat keadaan ketenagakerjaan pada Februari 2011 hingga Februari 2015 pada sektor pertanian di Provinsi Aceh mengalami penurunan dibandingkan dengan sektor indrustri dan jasa. Hal ini dapat dilihat pada tabel berikut:

Tabel 1. Jumlah Penduduk Usia 15 Tahun Keatas yang Bekerja Menurut Lapangan Pekerjaan Utama Pada Bulan Februari Tahun 2011-2015

\begin{tabular}{|c|c|c|c|c|c|c|}
\hline \multirow{2}{*}{$\begin{array}{c}\text { Lapangan Pekerjaan } \\
\text { Utama }\end{array}$} & \multicolumn{5}{|c|}{ Jumlah Petani (Ribuan) } & \multirow{2}{*}{$\begin{array}{c}\text { Rata-Rata Pertumbuhan } \\
\begin{array}{c}\text { (Growth Rate) Per } \\
\text { Tahun (\%) }\end{array} \\
2011-2015\end{array}$} \\
\hline & 2011 & 2012 & 2013 & 2014 & 2015 & \\
\hline $\begin{array}{l}\text { Pertanian } \\
\text { (Agriculture) }\end{array}$ & 903 & 980 & 1.000 & 956 & 860 & -1 \\
\hline $\begin{array}{l}\text { Industri Pengolahan } \\
\text { (Manufacturing) }\end{array}$ & 124 & 213 & 209 & 271 & 304 & 28 \\
\hline Jasa-jasa (Services) & 393 & 756 & 762 & 800 & 923 & 28,3 \\
\hline
\end{tabular}

Sumber : BPS Provinsi Aceh, 2015

Tabel 1 menunjukkan bahwa, rata-rata pertumbuhan jumlah penduduk yang bekerja di sektor pertanian sebagai lapangan kerja utama terus mengalami penurunan yaitu sebesar $1 \%$ per tahun. Seiring perubahan zaman, minat masyarakat bekerja di bidang pertanian semakin menurun. Minat masyarakat yang menurun untuk bekerja pada sektor pertanian disebabkan oleh beberapa faktor. Faktor-faktor tersebut dikelompokkan menjadi faktor intrinsik dan faktor ekstrinsik. Faktor intrinsik yaitu faktor ekonomi. Dari data BPS Sensus Pertanian (2013), mencatat bahwa rata-rata pendapatan untuk sektor pertanian di Indonesia adalah Rp. 12.413.920/tahun atau kurang lebih sebesar Rp. 1.034.500/bulan. Dengan jumlah pendapatan rata-rata petani di Indonesia ini yang lebih kecil dibandingkan keperluan untuk biaya kehidupan keluarga petani sehari-hari, hal ini yang menjadikan petani tidak bertahan lama pada profesinya. Kemudian faktor eksternal yaitu faktor yang berasal dari alam. Usahatani memiliki resiko yang tinggi seperti gagal panen karena sangat bergantung kepada kondisi alam yang tidak bisa diprediksi.

Kabupaten Aceh Barat sebagai daerah agraris memiliki potensi lahan pertanian yang besar. Sumber mata pencarian sebahagian besar masyarakat khususnya didaerah perdesaan adalah pada sub sektor pertanian tanaman pangan. Salah-satu tanaman pangan yang paling banyak dibudidayakan adalah padi sawah. 
Kecamatan Meureubo merupakan salah-satu Kecamatan yang menjadi sentra produksi padi di Kabupaten Aceh Barat, dengan luas tanam dan luas panen padi sawah yang terluas kedua setelah Kecamatan Kaway XVI. Hal ini dapat dilihat pada tabel sebagai berikut:

Tabel 2. Luas Tanam dan Luas Panen Padi Sawah Menurut Kecamatan Di Kabupaten Aceh Barat Tahun 2013

\begin{tabular}{|c|c|c|c|c|}
\hline \multirow{2}{*}{ No. } & \multirow{2}{*}{ Kecamatan } & \multicolumn{2}{|c|}{ Luas (Hektar) } & \multirow{2}{*}{ Total Luas (Hektar) } \\
\hline & & Tanam & Panen & \\
\hline 1. & Kaway XVI & 2.570 & 3.015 & 5.585 \\
\hline 2. & Meureubo & 1.857 & 1.503 & 3.360 \\
\hline 3. & Sama Tiga & 1.534 & 1.349 & 2.883 \\
\hline 4. & Woyla & 632 & 1.934 & 2.566 \\
\hline 5. & Bubon & 1.213 & 1.225 & 2.438 \\
\hline 6. & Arongan Lambalek & 1.731 & 696 & 2.427 \\
\hline 7. & Woyla Barat & 984 & 1.358 & 2.342 \\
\hline 8. & Pante Ceureumen & 426 & 1.142 & 1.568 \\
\hline 9. & Johan Pahlawan & 514 & 506 & 1.020 \\
\hline 10. & Woyla Timur & 590 & 407 & 997 \\
\hline 11. & Panton Reu & 152 & 413 & 565 \\
\hline 12. & Sungai Mas & 340 & 140 & 480 \\
\hline
\end{tabular}

Sumber: Aceh Barat dalam Angka 2014

Walaupun berada pada urutan kedua, persentase peningkatan produksi padi sawah pada tahun 2015 di Kecamatan Meureubo lebih tinggi dibandingkan dengan Kecamatan Kaway XVI. Data yang diperoleh dari Balai Penyuluhan Pertanian, Perikanan dan Kehutanan (BP3K) pada masing-masing Kecamatan, menunjukkan bahwa produksi tanaman pangan utama yaitu padi sawah di Kecamatan Meureubo pada tahun 2014 hingga tahun 2015 mengalami peningkatan, yaitu dari 4.800 ton menjadi 7.800 ton. Peningkatan tersebut berjumlah 3000 ton atau sebesar 38,46 \%. Sedangkan di Kecamatan Kaway XVI hanya meningkat sebesar 1,11\% pada tahun yang sama.

Pertumbuhan jumlah petani di Kecamaan Meureubo khususnya untuk petani tanaman pangan dilihat dari data programa BP3K Kecamatan Meureubo dari tahun 2011 hingga 2015 
mengalami penurunan jika dibandingkan dengan data pertumbuhan penduduk yang diperoleh dari BPS 2015. Lebih jelasnya dapat dilihat pada tabel berikut:

Tabel 3. Perkembangan Jumlah Tenaga Kerja Subsektor Pertanian Khususnya Petani Tanaman Pangan dan Jumlah Penduduk Kecamatan Meureubo Pada Tahun 20122016

\begin{tabular}{|l|c|c|c|c|c|c|}
\hline Keterangan & 2011 & 2012 & 2013 & 2014 & 2015 & $\begin{array}{c}\text { Rata-Rata } \\
\text { Perkembangan Per } \\
\text { Tahun (\%) }\end{array}$ \\
\hline $\begin{array}{l}\text { Jumlah Petani } \\
\text { Tanaman Pangan } \\
\text { (Orang) }\end{array}$ & 3.384 & 3.350 & 3.079 & 3.402 & 3.350 & $-0,25 \%$ \\
\hline $\begin{array}{l}\text { Jumlah Penduduk } \\
\text { (Orang) }\end{array}$ & $\begin{array}{c}27.11 \\
6\end{array}$ & 27.879 & $\begin{array}{c}28.71 \\
1\end{array}$ & 29.100 & 29.645 & $2,25 \%$ \\
\hline
\end{tabular}

Sumber: Programa BP3K Meureubo dan BPS Aceh Barat dalam Angka 2016.

Potensi Kecamatan Meureubo yang memiliki luasan lahan kedua terluas di Kabupaten Aceh Barat, serta dengan peningkatan produksi dan luas panen sepanjang tahun 2010-2014 yang cenderung meningkat di Aceh Barat, diharapkan jumlah petani khususnya yang bekerja pada usahatani padi juga ikut meningkat atau adanya regenerasi petani baru dari petani yang lama, supaya dapat memenuhi peningkatan kebutuhan pangan masyarakat yang semakin meningkat bersamaan dengan peningkatan jumlah penduduk disetiap tahunnya. Namun pada kenyataannya jumlah tenaga kerja khususnya untuk petani tanaman pangan di Kecamatan Meureubo justru mengalami penurunan.

Sebuah usaha, pada hakekatnya dilakukan untuk mendapatkan keuntungan. Keuntungan disini diartikan sebagai pendapatan. Pendapatan merupakan salah-satu faktor pertimbangan terbesar bagi petani dalam memilih untuk bekerja sebagai petani ataupun tidak. Suatu usaha yang dijalankan, baik itu usaha di sektor pertanian maupun industri dan jasa, harus diawali dengan adanya minat pada diri seseorang. Menurut Loekmono (2006) minat dapat diartikan sebagai kecenderungan untuk merasa tertarik atau terdorong untuk memperhatikan seseorang, sesuatu barang atau kegiatan dalam bidang-bidang tertentu.

Minat ini tidak timbul dengan sendirinya, akan tetapi minat akan timbul jika ada faktorfaktor yang mempengaruhinya, baik faktor yang berasal dari dalam diri individu ataupun faktor yang berasal dari luar diri individu.

\section{METODE PENELITIAN}

Penelitian ini dilaksanakan di Kecamatan Meureubo Kabupaten Aceh Barat. Penentuan daerah penelitian dilakukan secara sengaja (Purposive Sampling) dengan pertimbangan bahwa daerah tersebut merupakan salah satu sentra (pusat) produksi usahatani padi sawah.

Objek penelitian dalam penelitian ini adalah petani yang berusahatani padi sawah. Ruang lingkup penelitian ini terbatas pada besarnya pendapatan yang diperoleh petani dalam usahatani padi sawah dan faktor-faktor yang mempengaruhi minat petani terhadap usahatani 
padi sawah sebagai profesinya yaitu meliputi faktor Intrinsik (pendapatan dan pendidikan) dan faktor Ekstrinsik (lingkungan masyarakat dan lingkungan keluarga).

Teknik pengambilan desa sampel dilakukan secara sengaja (Purposive Sampling), dari 26 desa yang ada di Kecamatan Meureubo ditetapkan satu desa yang menjadi desa sampel yaitu Desa Ujong Tanoh Darat. Desa Ujong Tanoh Darat memiliki luas lahan sawah yaitu 97 Hektar dan petani dengan jumlah 245 orang.

Arikunto (2006), mengemukakan bahwa jika jumlah populasi kurang dari 100 orang maka sampelnya lebih baik diambil semua, tetapi apabila jumlah populasinya lebih besar dari 100 orang maka sampelnya dapat diambil antara 10-15\% atau 20-25\%. Berdasarkan hal tersebut, maka pengambilan sampel pada penelitian ini ditetapkan sebesar $10 \%$ yaitu sebanyak 25 petani dari jumlah petani pada desa sampel. Pengambilan petani sampel dilakukan secara acak sederhana (Simple Random Sampling).

Metode analisis pada penelitian ini adalah analisis pendapatan dan analisis statistik uji Chi-square. Untuk analisis pendapatan metode analisis yang digunakan adalah analisis usahatani dari Soekartawi 2002, sebagai berikut:

\section{Biaya Produksi}

$$
\mathrm{TC}=\mathrm{TFC}+\mathrm{TVC}
$$

Keterangan:

$\mathrm{TC}=$ Total biaya produksi $(\mathrm{Rp} / \mathrm{MT})$

$\mathrm{TFC}=$ Total biaya tetap $(\mathrm{Rp} / \mathrm{MT})$

$\mathrm{TVC}=$ Total biaya variabel $(\mathrm{Rp} / \mathrm{MT})$

\section{Penerimaan}

Keterangan:

$$
\mathrm{TR}=\mathrm{Y} . \mathrm{PY}
$$

$$
\begin{array}{ll}
\mathrm{TR} & =\text { Total Penerimaan }(\mathrm{Rp} / \mathrm{MT}) \\
\mathrm{Y} & =\text { Produksi }(\mathrm{Kg} / \mathrm{MT}) \\
\mathrm{PY} & =\text { Harga Produk }(\mathrm{Rp} / \mathrm{Kg})
\end{array}
$$

\section{Pendapatan}

Keterangan:

$$
\mathrm{I}=\mathrm{TR}-\mathrm{TC}
$$

$$
\begin{array}{ll}
\text { I } & =\text { Pendapatan }(\mathrm{Rp} / \mathrm{MT}) \\
\mathrm{TR} & =\text { Total Penerimaan }(\mathrm{Rp} / \mathrm{MT}) \\
\mathrm{TC} & =\text { Total Biaya }(\mathrm{Rp} / \mathrm{MT})
\end{array}
$$

Untuk melihat ukuran efisiensi penerimaan dari tiap rupiah yang dikeluarkan, digunatan analisis R/C Ratio (Revenue Cost Ratio). Rumus untuk analisis ini adalah sebagai berikut:

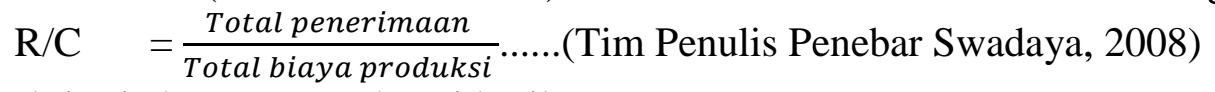

Dengan kriteria keputusan sebagai berikut:

1. Bila R/C > 1, maka usahatani padi sawah tersebut menguntungkan.

2. Bila $\mathrm{R} / \mathrm{C}<1$, maka usahatani padi sawah tersebut tidak menguntungkan atau rugi.

3. Bila $\mathrm{R} / \mathrm{C}=1$, maka usahatani padi sawah tersebut berada pada titik pulang atau titik impas yaitu Total Cost sama dengan Total Revenue. 
Untuk menguji pengaruh antara variabel faktor-faktor Intrinsik dan Ekstrinsik terhadap minat petani untuk berusahatani padi, digunakan uji statistik dengan menggunakan ChiSquare $\left(\chi^{2}\right)$, dengan rumus :

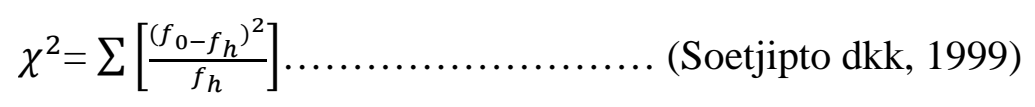

Dengan :

$$
\begin{aligned}
& \chi^{2}=\text { Nilai } \text { Chi Square } \\
& f_{0}=\text { besarnya frekuensi yang teramati pada kategori } \\
& f_{h}=\text { besarnya frekuensi yang diharapkan, ada kategori tertentu }
\end{aligned}
$$

Dengan ketentuan :

Jika $\chi^{2}$ hitung $>\chi_{\text {tabel }}^{2}$ pada taraf 0,05 maka terima $\mathrm{H}_{\mathrm{a}}$ tolak $\mathrm{H}_{0}$

Jika $\chi^{2}{ }_{\text {hitung }}<\chi^{2}$ tabel, pada taraf 0,05 maka terima $\mathrm{H}_{0}$ tolak $\mathrm{H}_{\mathrm{a}}$

Hipotesis untuk analisis Chi-square diformulasikan sebagai berikut :

$\mathrm{H}_{\mathrm{a}}$ : Faktor Intrinsik (pendapatan dan pendidikan) serta faktor Ekstrinsik (lingkungan keluarga dan lingkungan masyarakat) berpengaruh terhadap minat petani dalam berusahatani padi sawah.

$\mathrm{H}_{0}$ : Faktor Intrinsik (pendapatan dan pendidikan) serta faktor Ekstrinsik (lingkungan keluarga dan lingkungan masyarakat), tidak berpengaruh terhadap minat petani dalam berusahatani padi sawah.

\section{HASIL DAN PEMBAHASAN}

Berdasarkan hasil penelitian dilapangan didapatkan rata-rata penggunaan biaya produksi padi sawah adalah sebagai berikut:

Tabel 4. Rata-Rata Penggunaan Biaya Produksi pada Usahatani Padi Sawah di Desa Ujong Tanoh Darat Kecamatan Meureubo.

\begin{tabular}{|r|l|r|r|l|}
\hline \multicolumn{1}{|c|}{ No. } & \multicolumn{1}{|c|}{ Jenis Biaya } & \multicolumn{2}{|c|}{ Biaya Produksi (Rp) } & \multicolumn{2}{|l|}{$\begin{array}{l}\text { Nilai Total } \\
\text { (Rp/MT) }\end{array}$} \\
\cline { 3 - 5 } & $\begin{array}{c}\text { Biaya Variable } \\
\text { (Fixed Cost) }\end{array}$ & $\begin{array}{c}\text { Biaya Tetap } \\
\text { (Variable } \\
\text { Cost) }\end{array}$ & \\
\hline 1. & Sarana produksi & 1.633 .993 & - & \\
\hline 2. & Tenaga Kerja & 5.903 .928 & - & \\
\hline 3. & Penyusutan Alat & & 148.479 & \\
\hline 4. & Biaya-biaya lain & 2.518 .249 & & \\
\hline & Jumlah (Rp) & 10.056 .170 & 148.479 & \\
\hline
\end{tabular}

Sumber : Data Primer (Diolah), 2016 
Berdasarkan Tabel 4 dapat diketahui bahwa besarnya biaya produksi rata-rata yang dikeluarkan oleh petani adalah sebesar Rp. 10.204.649/Ha/MT. Biaya produksi paling besar yang dikeluarkan oleh petani terdapat pada biaya penggunaan tenaga kerja yaitu sebesar Rp. 5.903.928/Ha/MT dan biaya terendah yang dikeluarkan adalah untuk biaya penyusutan alat pertanian yaitu sebesar Rp. 148.479/Ha/MT.

Produksi merupakan hasil penerimaan kotor dalam bentuk fisik dari proses produksi yang telah dilakukan oleh petani sebagai pemilik usahatani padi sawah, produksi padi sawah dinyatakan dalam satuan $\mathrm{Kg} / \mathrm{Ha} / \mathrm{MT}$. Total penerimaan adalah total produksi padi sawah yang dikalikan dengan harga di tingkat petani, dinyatakan dalam satuan Rp/Ha/MT. Rata-rata produksi dan total penerimaan didaerah penelitian adalah sebagai berikut:

Tabel 5. Rata-Rata Produksi dan Total Penerimaan Usahatani Padi Sawah di Desa Ujong Tanoh Darat Kecamatan Meureubo.

\begin{tabular}{|l|l|c|r|r|}
\hline \multirow{2}{*}{ No. } & \multicolumn{1}{|c|}{ Keterangan } & Satuan & \multicolumn{2}{c|}{ Jumlah Rata-Rata } \\
\cline { 3 - 5 } & & & Per Petani & Per 1 Ha \\
\hline 1 & Luas Lahan & $\mathrm{Ha}$ & 0,67 & 4.775 \\
\hline 2 & Produksi & $\mathrm{Kg} / \mathrm{Ha} / \mathrm{MT}$ & 3.205 & 4.500 \\
\hline 3 & Harga Jual & $\mathrm{Rp} / \mathrm{Kg}$ & 4.500 & 21.489 .525 \\
\hline 4 & Penerimaan & $\mathrm{Rp} / \mathrm{Ha} / \mathrm{MT}$ & 14.422 .500 & \\
\hline
\end{tabular}

Sumber : Data Primer (Diolah), 2016

Berdasarkan Tabel 5 dapat diketahui bahwa jumlah penerimaan yang diperoleh per petani dari hasil produksi padi sawah yang dilakukan selama satu kali masa tanam adalah sebesar Rp. 14.422.500/Ha/MT. Sedangkan untuk perhitungan rata-rata per satuan lahan yaitu per $1 \mathrm{Ha}$ penerimaan yang diperoleh petani adalah sebesar Rp. 21.489.525/Ha/MT.

\section{Analisis Pendapatan}

Rata-rata pendapatan petani pada usahatani padi sawah di daerah penelitian dihitung dengan menggunakan rumus sebagai berikut:

$\mathrm{I} \quad=\mathrm{TR}-\mathrm{TC}$

$$
\begin{aligned}
& =\text { Rp. } 21.489 .525-\text { Rp. 10.204.649 } \\
& =\text { Rp. 11.284.876 }
\end{aligned}
$$

Sedangkan untuk mengetahui apakah usahatani padi sawah yang dilakukan oleh petani di daerah penelitian menguntungkan atau tidak bagi petani, dapat dihitung dengan menggunakan analisis R/C Ratio (Revenue Cost Ratio), dengan rumus sebagai berikut:

$$
\begin{aligned}
\mathrm{R} / \mathrm{C} & =\frac{\text { Total penerimaan }}{\text { Total biaya produksi }} \\
& =\frac{21.489 .525}{10.204 .649} \\
& =2,11
\end{aligned}
$$

Hasil perhitungan menunjukkan nilai R/C Ratio adalah sebesar 2,11 yang berarti bahwa nilai R/C Ratio hitung lebih besar dari $1(\mathrm{R} / \mathrm{C}>1)$. Sehingga dapat disimpulkan bahwa usahatani padi sawah di Desa Ujong Tanoh Darat Kecamatan Meureubo Kabupaten Aceh 
Barat adalah menguntungkan atau layak untuk diusahakan oleh petani. Nilai R/C Ratio sebesar 2,11 juga menunjukkan bahwa setiap pengeluaran dari petani sebesar Rp. 100/Ha/MT yang digunakan untuk biaya produksi usahatani padi sawah maka akan menambah penerimaan bagi petani sebesar Rp. 211/Ha/MT.

\section{Analisis Faktor-Faktor yang Mempengaruhi Minat Petani}

Hasil analisis uji Chi-Square untuk faktor-faktor yang mempengaruhi minat petani terhadap usahatani padi sawah didaerah penelitian lebih jelasnya dapat dilihat pada Tabel 5 berikut:

Tabel 6. Hasil Uji Chi-Square Faktor-Faktor yang Mempengaruhi Minat Petani Terhadap Usahatani Padi Sawah di Kecamatan Meureubo Kabupaten Aceh Barat

\begin{tabular}{|l|l|c|c|c|c|}
\hline No & $\begin{array}{l}\text { Faktor yang } \\
\text { Mempengaruhi Minat }\end{array}$ & $\begin{array}{c}\text { Nilai Chi- } \\
\text { SquareHit } \\
\text { ung }\end{array}$ & $\begin{array}{c}\text { Nilai Chi- } \\
\text { Square Tab } \\
\text { el }\end{array}$ & Asymp.Sig & Keterangan \\
\hline 1 & Pendapatan & 19,048 & 9,488 & 0,001 & Signifikan \\
\hline 2 & Pendidikan & 7,544 & 9,488 & 0,110 & Tidak Signifikan \\
\hline 3 & Lingkungan Keluarga & 21,035 & 9,488 & 0,000 & Signifikan \\
\hline 4 & Lingkungan Masyarakat & 10,333 & 9,488 & 0,035 & Signifikan \\
\hline
\end{tabular}

Sumber : Data Primer (Diolah), 2016

Tabel 6 diatas menunjukkan bahwa faktor pendapatan, lingkungan keluarga dan lingkungan masyarakat merupakan faktor yang berpengaruh signifikan. Hal ini dikarenakan nilai Chi-Square hitung yang didapat lebih besar dibandingkan nilai Chi-Square tabel. Kemudian nilai Asymp. Sig yang diperoleh lebih kecil dari nilai signifikasi 0,05. Sedangkan faktor pendidikan merupakan faktor yang tidak mempengaruhi minat petani terhadap usahatani padi sawah. Hal ini juga dikarenakan nilai Chi-Square hitung yang didapat lebih dibandingkandengan nilai Chi-Square tabel. Kemudian nilai Asymp. Sig yang diperoleh lebih besar dibandingkan dengan nilai signifikasi yaitu 0,05 .

\section{KESIMPULAN DAN SARAN}

Hasil penelitian menunjukkan bahwa rata-rata pendapatan usahatani padi sawah di Desa Ujong Tanoh Darat Kecamatan Meureubo yang diperoleh petani adalah sebesar Rp.11.284.876/MT. Nilai R/C didapat sebesar 2,11 artinya, usahatani padi sawah di Desa Ujong Tanoh Darat Kecamatan Meureubo Kabupaten Aceh Barat menguntungkan atau layak untuk diusahakan. Kajian ini mengungkapkan bahwa satu dari faktor internal yaitu faktor pendapatan berpengaruh terhadap minat petani, kemudian faktor eksternal yang terdiri dari faktor lingkungan keluarga dan lingkungan masyarakat, keduanya juga berpengaruh terhadap minat petani. Sedangkan faktor internal lainnya yaitu faktor pendidikan merupakan satusatunya faktor yang tidak berpengaruh terhadap minat petani dalam berusahatani padi sawah. Faktor lingkungan keluarga merupakan faktor yang berpengaruh dominan terhadap minat petani berdasarkan nilai asymp. Sig yang didapatkan lebih kecil dari taraf signifikasi $(0,05)$ yaitu 0,000 , kemudian diikuti dengan faktor pendapatan $=0,001$ dan lingkungan keluarga $=$ 0,003 .

Diharapkan bagi petani agar dapat tetap melanjutkan usahatani padi sawah karena usahatani padi sawah di Desa Ujong Tanoh Darat Kecamatan Meureubo diketahui menguntungkan berdasarkan analisis pendapatan usahatani dan perhitungan R/C Ratio yang 
didapatkan. Diharapkan untuk petani agar dapat membuat pembukuan pada usahatani yang dijalankan agar dapat mengetahui besar kecilnya jumlah penerimaan yang didapat berdasarkan biaya yang dikeluarkan. Kemudian diharapkan untuk dilakukan penelitian selanjutnya terkait pengaruh usia terhadap minat petani dalam berusahatani padi.

\section{DAFTAR PUSTAKA}

Arikunto, S. 2006. Prosedur Penelitian. Jakarta: PT Rineka Cipta.

Balai Penyuluhan Pertanian, Perikanan dan Kehutanan (BP3K). 2016. Programa Penyuluhan Pertanian Kecamatan Meureubo. Meureubo: Aceh Barat.

Balai Penyuluhan Pertanian, Perikanan dan Kehutanan (BP3K). 2016. Programa Penyuluhan Pertanian Kecamatan Kaway XVI. Meureubo: Aceh Barat.

BPS. 2013. Data Hasil Sensus Pertanian (BPS_ST13)2013. Badan Pusat Statistik

BPS. 2015. Provinsi Aceh Dalam Angka 2015. Badan Pusat Statistik: Banda Aceh.

Loekmono. 2006. Pengenalan Diri dalam Kepemimpinan Pendidikan. Semarang: YPSAK.

Soekartawi. 2002. Analisis Usahatani. Jakarta: Universitas Indonesia Press.

Soetjipto, Widyono dkk. 1999. Teknik Statistika untuk Bisnis dan Ekonomi. Edisi ke Sembilan Jilid 2. Jakarta: Erlangga.

Tim Penulis Penebar Swadaya. 2008. Agribisnis Pendapatan Perikanan. Jakarta: Penebar Swadaya.

. 2015. Aceh Barat Dalam Angka 2015. Badan Pusat Statistik Provinsi Aceh. . 2016. Aceh Barat Dalam Angka 2016. Badan Pusat Statistik Provinsi Aceh.

2015. Berita Resmi Statistik. Ketenagakerjaan Februari 2015. Badan Pusat Statistik Provinsi Aceh. 